\title{
Two New Oleanane Saponins from Chiococca alba (L.) Hitch.
}

\author{
Ricardo M. Borges, ${ }^{*}, a$ Luzineide W. Tinoco, ${ }^{a}$ José D. de Souza Filho, ${ }^{b}$ \\ Nancy dos Santos Barbic and Antonio Jorge R. da Silva ${ }^{a}$
}

${ }^{a}$ Núcleo de Pesquisas de Produtos Naturais and ${ }^{c}$ Faculdade de Farmácia, Centro de Ciências da Saúde, Universidade Federal do Rio de Janeiro, 21941-590 Rio de Janeiro-RJ, Brazil

${ }^{b}$ Departamento de Química, Instituto de Ciências Exatas, Universidade Federal de Minas Gerais, 31270-901 Belo Horizonte-MG, Brazil

\begin{abstract}
Duas saponinas triterpênicas foram isoladas do extrato etanólico das raízes de Chiococca alba (L.) Hitch. (Rubiaceae). Suas estruturas foram elucidadas por RMN de ${ }^{1} \mathrm{H}$ e ${ }^{13} \mathrm{C} 1 \mathrm{D}$ e $2 \mathrm{D}$ e por espectrometria de massas de alta resolução com ionização por eletronebulização como 3-O- $\beta$-D-glucopiranurosil-3- $\beta$-hidroxiolean-12,15-dien-28-oato de $O$ - $\alpha$-D-apiofuranosil $(1 \rightarrow 3)$ $[\alpha$-D-apiofuranosil $(1 \rightarrow 4)]$ - $\alpha$-L-rhamnopiranosil $(1 \rightarrow 2)$ - $\alpha$-L-arabinopiranosila $(\mathbf{1})$ e $3-O-\beta$-Dglucopiranurosil-3- $\beta$-hidroxiolean-12,15-dien-28-oato de $28-O-\alpha$-D-apiofuranosil $(1 \rightarrow 3)$ - $\alpha$-Lrhamnopiranosil $(1 \rightarrow 2)-\alpha$-L-arabinopiranosila $(2)$.
\end{abstract}

Two triterpene saponins were isolated from the ethanolic extract of the roots of Chiococca alba (L.) Hitch (Rubiaceae). Their structures were determined by ${ }^{1} \mathrm{H}$ and ${ }^{13} \mathrm{C} 1 \mathrm{D}$ and $2 \mathrm{D} \mathrm{NMR}$ and high resolution electrospray mass spectrometry as $3-O$ - $\beta$-D-glucopyranurosyl-3 $\beta$-hydroxyolean12,15-dien-28-oic acid 28- $O$ - $\alpha$-D-apiofuranosyl $(1 \rightarrow 3)$-[ $\alpha$-D-apiofuranosyl $(1 \rightarrow 4)]$ - $\alpha$-Lrhamnopyranosyl $(1 \rightarrow 2)-\alpha$-L-arabinopyranosyl ester $(\mathbf{1})$ and 3-O- $\beta$-D-glucopyranurosyl-3 $\beta$ hydroxyolean-12,15-dien-28-oic acid 28-O- $\alpha$-D-apiofuranosyl $(1 \rightarrow 3)$ - $\alpha$-L-rhamnopyranosyl

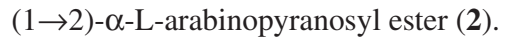

Keywords: Chiococca alba, cainca, Rubiaceae, triterpene saponins

\section{Introduction}

Chiococca alba (L.) Hitch. (Rubiaceae), commonly known as "cainca" in Brazil, is a tropical and sub-tropical shrub spread all over the American continent. Its root bark is used in Brazilian traditional medicine for the treatment of several illnesses. ${ }^{1}$ Toxicological studies demonstrated absence of mutagenic activity in the ethanolic extract of the roots of C. alba and also low acute and sub acute toxicity by the oral route. Nevertheless, toxicity by parenteral routes was indeed pronounced. ${ }^{2}$

Previous works on C. alba reported the occurrence of lignans, coumarins, ketoalcohols, ${ }^{3}$ triterpenes, ${ }^{4}$ iridoids, ${ }^{5}$ flavonoids, ${ }^{6}$ two quinoline alkaloids ${ }^{7}$ and a nor-secopimarane. $^{8}$

The present paper reports for the first time the isolation and structure elucidation of two triterpenoidal saponins from the ethanolic extract of the roots of $C$. alba.

*e-mail: rmborges@nppn.ufrj.br

\section{Experimental}

General experimental procedures

Optical rotations were measured on a Perkin Elmer model 243B polarimeter. Infrared spectra were recorded on a Nicolet Magna spectrometer. ${ }^{1} \mathrm{H}$ NMR and ${ }^{13} \mathrm{C}$ NMR spectra were recorded at 200 and $50 \mathrm{MHz}$ (Varian Gemini 200), at 400 and $100 \mathrm{MHz}$ (Bruker DRX 400) and at 600 and $150 \mathrm{MHz}$ (Bruker DRX 600) in methanol- $d_{4}$ and chloroform- $d_{1}$ with TMS as internal standard.

The chemical shifts are reported in ppm. 1D and 2D experiments were made with the standard software provided. HRES/ESI/TOF MS analyses were made with a Bruker Daltonics microTOF instrument. Column chromatography: ODS silica gel (Aldrich Chemical Company, Inc); TLC: silica gel $(0.25 \mathrm{~mm}$ precoated plates $60 \mathrm{~F}_{254}$, Merck). For preparative HPLC a $7.6 \times 300 \mathrm{~mm}$ ODS column and UV detection at $210 \mathrm{~nm}$ were used. GC-MS analyses were recorded on a Shimadzu QP5000 
GC/MS instrument (5\% phenylmethyl silicone column, $30 \mathrm{~m} \times 0.25 \mathrm{~mm}$ ID, $0.25 \mu \mathrm{m}$ film thickness; programmed column temperature from 110 to $\left.290{ }^{\circ} \mathrm{C}, 5^{\circ} \mathrm{C} \mathrm{min}^{-1}\right)$.

\section{Plant material}

Samples of C. alba were collected in Nova Friburgo, Rio de Janeiro, Brazil. The botanical identification was provided by Dr. Sebastião Neto, and a voucher specimen (RB395399) is deposited in the Herbarium of Rio de Janeiro Botanical Garden.

\section{Extraction and isolation}

Air-dried and powdered roots of C. alba (400 g) were extracted with ethanol. The extract was evaporated; the residue obtained (12 g) was suspended in water and successively partitioned with methylene chloride and butanol. The butanol fractions were combined, evaporated and the residue $(4 \mathrm{~g})$ was suspended in methanol and subjected to controlled precipitation with diethyl ether. The precipitate $(2 \mathrm{~g})$ was fractionated by column chromatography (octadecylsilane, $60 \times 20 \mathrm{~cm}$ ) using $\mathrm{H}_{2} \mathrm{O}$ with increasing proportions of methanol ( $0 \%$ to $100 \%)$ to afford 10 fractions. TLC tests carried out with Liebermann-Bouchard and sulfuric orcinol reagents together with the observation the abundant foam formation, allowed the identification of the saponin enriched fractions. Further purification was carried out with reversed phase (octadecylsilane) preparative HPLC using methanol: $0.02 \%$ aqueous trifluoroacetic acid $(60: 40 ; \mathrm{v} / \mathrm{v})$ to afford chiococcasaponin I (78 mg) and chiococcasaponin II (48 mg).

\section{Chiococcasaponin I (1)}

Amorphous white solid, UV transparent, $[\alpha]_{D}^{25}=-58$ (MeOH; $c$ 1). IR (KBr) $v_{\max } / \mathrm{cm}^{-1}: 3428,2944,1732,1040$, 986. ${ }^{1} \mathrm{H}$ NMR (methanol- $d_{4}, 400 \mathrm{MHz}$ ) and ${ }^{13} \mathrm{C}$ NMR (methanol- $d_{4}, 100 \mathrm{MHz}$ ) (Table 1). HRES/ESI/TOF MS (negative mode) calculated for $\mathrm{C}_{57} \mathrm{H}_{88} \mathrm{O}_{25}$, [M-H]-: $\mathrm{m} / \mathrm{z}$ 1171.5536; found: 1171.5546. HRES/ESI/TOF MS (positive mode), calculated for $\mathrm{C}_{57} \mathrm{H}_{88} \mathrm{O}_{25} \mathrm{Na},[\mathrm{M}+\mathrm{Na}]^{+}: \mathrm{m} / \mathrm{z}$ 1195.5512; found: 1195.5513 .

\section{Chiococcasaponin II (2)}

Amorphous white solid, UV transparent, $[\alpha]_{\mathrm{D}}^{25}=-46$ $\left(\mathrm{MeOH} ; c\right.$ 1). IR (KBr) $v_{\max } / \mathrm{cm}^{-1}: 3426,2946,1736,1137$, $1077,1053,1034,980 .{ }^{1} \mathrm{H}$ NMR (methanol- $d_{4}, 400 \mathrm{MHz}$ ) and ${ }^{13} \mathrm{C}$ NMR (methanol- $d_{4}, 100 \mathrm{MHz}$ ) (Table 1). HRES/ ESI/TOF MS (negative mode) calculated for $\mathrm{C}_{52} \mathrm{H}_{80} \mathrm{O}_{21}$, [M-H] $]^{-}: \mathrm{m} / z$ 1039.5114; found: 1039.5122. HRES/ESI/TOF MS (positive mode), calculated for $\mathrm{C}_{52} \mathrm{H}_{80} \mathrm{O}_{21} \mathrm{Na}$, $[\mathrm{M}+\mathrm{Na}]^{+}$: $\mathrm{m} / \mathrm{z} 1063.5089$ found: 1063.5084 .

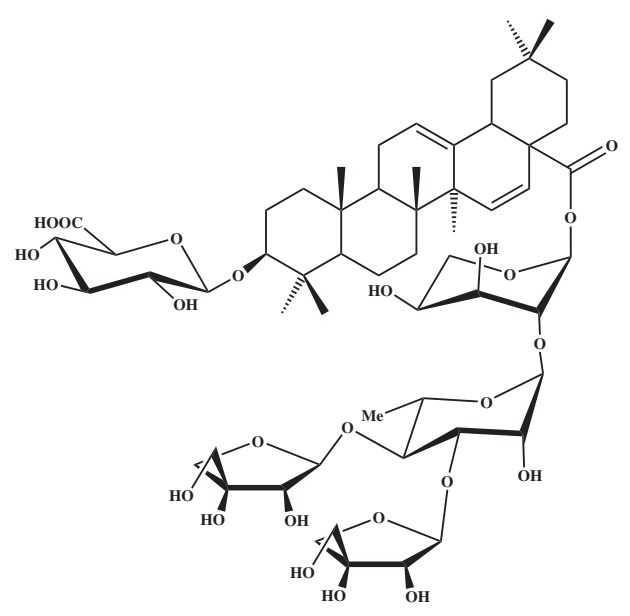

1 Chiococcasaponin I

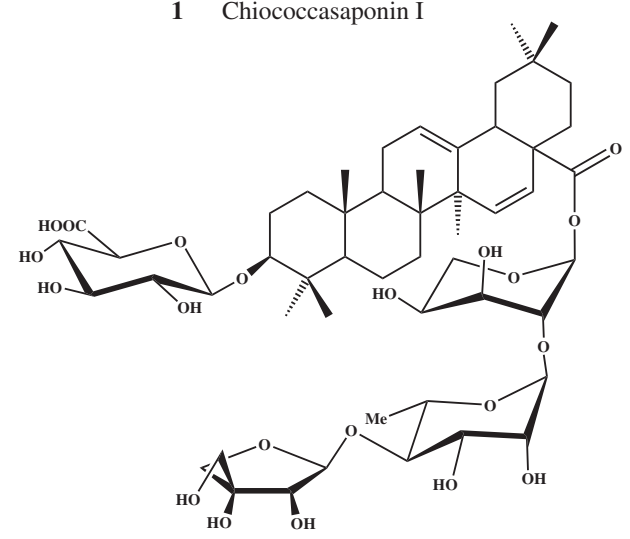

2 Chiococcasaponin II

\section{Acid hydrolysis}

A solution of each saponin ( $5 \mathrm{mg}$ per $2 \mathrm{~mL}$ of $0.5 \mathrm{~mol} \mathrm{~L}^{-1}$ aqueous TFA) was poured in a Kontes heavy wall pressure resistant vessel and heated for $2 \mathrm{~min}$ in a microwave oven at full power. The reaction mixture was cooled, diluted with water and extracted with diethyl ether. The organic layer was concentrated under vacuum and the residue was methylated with diazomethane. $3 \beta$-hydroxyolean- 12 , 15-dien-28-oate methyl ester was identified by MS and NMR as the aglycone for both saponins.

MS (EI, 70eV) $\mathrm{m} / \mathrm{z} 468$ (2\%); 260 (42\%); 245 (14\%); 231; 207; 201 (100\%); 187 (14\%); 173; 157; 145; 131 (46\%); $119 ; 105 ; 95 ; 81 ; 69 ; 55 .{ }^{13} \mathrm{C}$ NMR (chloroform- $d_{l}$, $100 \mathrm{MHz}): 16.1(\mathrm{C}-25) ; 17.0$ (C-23); 18.3 (C-26); 19.6 (C6); 23.6 (C-30); 24.4 (C-11); 25.1 (C-27); 27.1 (C-2); 28.5 (C-24); 31.3 (C-20); 33.8 (C-22); 33.9 (C-29); 33.9 (C-17); 34.1 (C-7); 35.7 (C-21); 38.2 (C-10); 39.8 (C-1); 40.3 (C4); 41.3 (C-8); 43.5 (C-18); 44.6 (C-19); 45.6 (C-14); 48.7 (C-9); 57.2 (C-5); 91.2 (C-3); 124.7 (C-12); 128.6 (C-15); 137.8 (C-16); 141.5 (C-13); 176.1 (C-28).

The aqueous phase was lyophilized, the monosaccharides were reduced with sodium borohydride in water and the 
Table 1. Carbon and proton NMR data for Chiococcasaponins I and II (100 and $400 \mathrm{MHz}, \mathrm{CD}_{3} \mathrm{OD}$, internal TMS

\begin{tabular}{|c|c|c|c|c|}
\hline \multirow[b]{2}{*}{ Carbon } & \multicolumn{2}{|c|}{ Chiococcasaponin I } & \multicolumn{2}{|c|}{ Chiococcasaponin II } \\
\hline & ${ }^{1} \mathrm{H}$ & ${ }^{13} \mathrm{C}$ & ${ }^{1} \mathrm{H}$ & ${ }^{13} \mathrm{C}$ \\
\hline $1 \mathrm{CH}_{2}$ & $1.60 / 1.01$ & 39.7 & $1.60 / 1.01$ & 39.8 \\
\hline $2 \mathrm{CH}_{2}^{2}$ & $1.87 / 1.7$ & 27.1 & $1.85 / 1.68$ & 27.1 \\
\hline $3 \mathrm{CHOH}$ & $\begin{array}{c}3.17(d d, J 11.1 / \\
3.5 \mathrm{~Hz})\end{array}$ & 91.1 & $\begin{array}{c}3.17(d d, J 11.1 / \\
3.5 \mathrm{~Hz})\end{array}$ & 91.2 \\
\hline $4 \mathrm{C}$ & -- & 40.2 & -- & 40.3 \\
\hline $5 \mathrm{CH}$ & 0.82 & 57.0 & 0.82 & 57.2 \\
\hline $6 \mathrm{CH}_{2}$ & 1.45 & 19.4 & 1.60 & 19.6 \\
\hline $7 \mathrm{CH}_{2}$ & $1.68 / 1.54$ & 33.8 & $1.60 / 1.50$ & 34.1 \\
\hline $8 \mathrm{C}^{2}$ & -- & 41.2 & -- & 41.3 \\
\hline $9 \mathrm{CH}$ & 1.66 & 48.7 & 1.65 & 48.7 \\
\hline $10 \mathrm{C}$ & -- & 38.2 & -- & 38.2 \\
\hline $11 \mathrm{CH}_{2}$ & $1.97 / 1.86$ & 24.3 & $1.95 / 1.84$ & 24.4 \\
\hline $12 \mathrm{CH}^{2}$ & 5.44 & 124.6 & 5.46 & 124.7 \\
\hline $13 \mathrm{C}$ & -- & 141.6 & -- & 141.5 \\
\hline $14 \mathrm{C}$ & -- & 45.5 & -- & 45.6 \\
\hline $15 \mathrm{CH}$ & 5.54 & 128.7 & 5.54 & 128.6 \\
\hline $16 \mathrm{CH}$ & 5.67 & 137.5 & 5.66 & 137.8 \\
\hline $17 \mathrm{C}$ & -- & 33.6 & -- & 33.9 \\
\hline $18 \mathrm{CH}$ & $\begin{array}{c}3.92(d d, J 13.1 / \\
2.78 \mathrm{~Hz})\end{array}$ & 43.4 & $\begin{array}{c}2.93(d d, J 13.1 / \\
2.78 \mathrm{~Hz})\end{array}$ & 43.5 \\
\hline $19 \mathrm{CH}_{2}$ & $1.58 / 1.10$ & 44.6 & $1.56 / 1.09$ & 44.6 \\
\hline $20 \mathrm{C}$ & -- & 31.3 & -- & 31.3 \\
\hline $21 \mathrm{CH}_{2}$ & 1.26 & 35.6 & 1.26 & 35.7 \\
\hline $22 \mathrm{CH}_{2}^{2}$ & 1.81 & 33.6 & 1.80 & 33.8 \\
\hline $23 \mathrm{CH}_{3}$ & $0.86(s)$ & 16.9 & $0.85(s)$ & 17.0 \\
\hline $24 \mathrm{CH}_{3}$ & $1.06(s)$ & 28.4 & $1.06(s)$ & 28.5 \\
\hline $25 \mathrm{CH}_{3}$ & $0.88(s)$ & 16.0 & $0.88(s)$ & 16.1 \\
\hline $26 \mathrm{CH}_{3}$ & $0.64(s)$ & 18.3 & $0.63(s)$ & 18.3 \\
\hline $27 \mathrm{CH}_{3}$ & $1.17(s)$ & 25.0 & $1.16(s)$ & 25.1 \\
\hline $28 \mathrm{C}=\mathrm{O}$ & -- & 176.1 & -- & 176.1 \\
\hline $29 \mathrm{CH}_{3}$ & $0.90(s)$ & 33.6 & $0.90(s)$ & 33.9 \\
\hline $30 \mathrm{CH}_{3}$ & $0.93(s)$ & 23.5 & $0.93(s)$ & 23.6 \\
\hline \multicolumn{5}{|l|}{ Ara at C-28 } \\
\hline $1 \mathrm{CH}$ & $5.39(d, J 4.4 \mathrm{~Hz})$ & 94.4 & $5.46(d, J 5.4 \mathrm{~Hz})$ & 94.4 \\
\hline $2 \mathrm{CH}$ & 3.80 & 75.4 & 3.78 & 75.4 \\
\hline $3 \mathrm{CH}$ & 3.51 & 72.5 & 3.76 & 72.5 \\
\hline $4 \mathrm{CH}$ & 3.81 & 68.1 & 3.82 & 67.4 \\
\hline $5 \mathrm{CH}_{2}$ & $3.56 / 3.86$ & 64.9 & $5.51 / 3.88$ & 64.0 \\
\hline \multicolumn{5}{|l|}{ Rha } \\
\hline $1 \mathrm{CH}$ & $5.12(s)$ & 101.4 & $5.06(s)$ & 101.7 \\
\hline $2 \mathrm{CH}$ & 3.95 & 72.3 & 3.79 & 72.7 \\
\hline $3 \mathrm{CH}$ & 3.76 & 80.8 & 3.86 & 71.7 \\
\hline $4 \mathrm{CH}$ & 3.62 & 79.2 & 3.52 & 80.2 \\
\hline $5 \mathrm{CH}$ & 3.83 & 69.0 & 3.75 & 69.2 \\
\hline $6 \mathrm{CH}_{3}$ & $1.27(d, J 6 \mathrm{~Hz})$ & 18.5 & $1.28(d, J 6 \mathrm{~Hz})$ & 18.5 \\
\hline \multicolumn{5}{|l|}{ Api } \\
\hline $1 \mathrm{CH}$ & $\begin{array}{c}5.19 \\
(d, J=1.7 \mathrm{~Hz})\end{array}$ & 112.5 & $\begin{array}{c}5.33 \\
(d, J=1.7 \mathrm{~Hz})\end{array}$ & 111.6 \\
\hline $2 \mathrm{CH}$ & 4.04 & 79.3 & 3.92 & 78.6 \\
\hline $3 \mathrm{C}$ & -- & 80.7 & -- & 80.6 \\
\hline $4 \mathrm{CH}_{2}$ & $3.76 / 4.05$ & 74.9 & $3.76 / 4.00$ & 75.0 \\
\hline $5 \mathrm{CH}_{2}$ & 3.59 & 65.3 & 3.58 & 65.5 \\
\hline \multicolumn{5}{|l|}{ Api } \\
\hline $1 \mathrm{CH}$ & $5.29(d, J 1.7 \mathrm{~Hz})$ & 112.2 & -- & -- \\
\hline $2 \mathrm{CH}$ & 3.95 & 78.3 & -- & -- \\
\hline $3 \mathrm{C}$ & -- & 80.4 & -- & -- \\
\hline $4 \mathrm{CH}_{2}$ & $3.77 / 4.05$ & 75.1 & -- & -- \\
\hline $5 \mathrm{CH}_{2}$ & 3.56 & 65.5 & -- & -- \\
\hline \multicolumn{5}{|c|}{ GlcUA at C-3 } \\
\hline $1 \mathrm{CH}$ & $4.38(d, J 7.3 \mathrm{~Hz})$ & 107.0 & $4.38(d, J 7.3 \mathrm{~Hz})$ & 107.0 \\
\hline $2 \mathrm{CH}$ & 3.24 & 75.3 & 3.24 & 75.5 \\
\hline $3 \mathrm{CH}$ & 3.37 & 77.7 & 3.37 & 77.9 \\
\hline $4 \mathrm{CH}$ & 3.51 & 73.3 & 3.51 & 73.4 \\
\hline $5 \mathrm{CH}$ & 3.76 & 75.4 & 3.79 & 75.4 \\
\hline $6 \mathrm{C}(\mathrm{OH})=\mathrm{O}$ & -- & 176.0 & -- & 176.0 \\
\hline
\end{tabular}

resulting alditols were acetylated (acetic anhydride/ pyridine, $1 \mathrm{~h}$ ). The alditol acetates of arabinose, rhamnose and apiose were identified by direct comparison with authentic samples using GC/MS. The monosaccharides were also characterized by TLC on silica gel (butanol/acetic acid/water, 2:1:1). The spots on TLC plates were visualized by spraying with sulphuric-orcinol solution followed by heating. Glucuronic acid, arabinose and rhamnose were identified by comparison with authentic samples.

\section{Results and Discussion}

The HRES/ESI MS (positive mode) of chiococcasaponin I (1) exhibited a pseudomolecular ion peak $[\mathrm{M}+\mathrm{Na}]^{+}$at $\mathrm{m} / \mathrm{z}$ 1195.5513 and the negative mode HRES/ESI-MS exhibited a pseudomolecular ion peak $[\mathrm{M}-\mathrm{H}]^{-}$at $\mathrm{m} / \mathrm{z}$ 1171.5546, both peaks being consistent with the molecular formula $\mathrm{C}_{57} \mathrm{H}_{88} \mathrm{O}_{25}$. Acid hydrolysis of $\mathbf{1}$ afforded the aglycone and the following monosaccharides: glucuronic acid, rhamnose, arabinose and apiose which were identified by GC/MS and TLC analysis. Due to the fact that apiose is a branched-chain sugar, incomplete acetylation is often observed for it when standard alditol acetylation conditions are utilized. This leads to the observation of two peaks for the partially acetylated apiose alditols in the GC/ MS analyses. This behavior has already been described by Harris. ${ }^{9}$ The aglycone had its structure confirmed as $3 \beta$-hydroxyolean-12, 15-dien-28-oic acid by comparison of its ${ }^{1} \mathrm{H}$ and ${ }^{13} \mathrm{C}$ NMR spectra with literature data. ${ }^{4}$ This is the first report on the occurrence of a 15,16 unsaturated oleanolic acid saponin. ${ }^{1} \mathrm{H}$ and ${ }^{13} \mathrm{C}$ NMR data are shown in Table 1. 1D ${ }^{1} \mathrm{H}$ and ${ }^{13} \mathrm{C}$ NMR, DEPT and HSQC spectra confirmed the presence of five sugar residues corresponding to anomeric protons/carbons at 4.38/107.0, 5.12/101.4, 5.39/94.4, 5.19/112.5 and 5.29/112.2 ppm respectively. The anomeric proton at $4.38 \mathrm{ppm}(\mathrm{d}, J 7.3 \mathrm{~Hz})$ displayed an array of correlations with signals at 3.24, 3.37, 3.51 and $3.76 \mathrm{ppm}$ in the TOCSY spectrum. These ${ }^{1} \mathrm{H}$ chemical shifts and the respective correlated carbons (HSQC) at: 75.3, 77.7, 73.3, 75.4 ppm together with the carboxyl group appearing at $176.0 \mathrm{ppm}$ are consistent with the presence of a $\beta$-glucopyranurosyl residue. A further correlation, observed in the $\mathrm{HMBC}$ spectrum between the proton at 4.38 and the carbon at $91.1 \mathrm{ppm}(\mathrm{C}-3)$ confirmed the location of the $\beta$-glucopyranurosyl residue at $\mathrm{C}-3$. Another correlation, between protons at 4.38 and 3.17 (aglycone $\mathrm{H}-3$ ), observed in the T-ROESY spectrum reinforced the above deduction. The configurations at the anomeric carbons were assigned with the help of a NMR $J$-resolved heteronuclear experiment, on the basis of the measured ${ }^{1} J_{\mathrm{C}, \mathrm{H}}: 164 \mathrm{~Hz}$ for the signal at $94.4 \mathrm{ppm}(\mathrm{C}-1, \mathrm{Ara}), 170.6 \mathrm{~Hz}$ for the signal 
at $101.4 \mathrm{ppm}(\mathrm{C}-1, \mathrm{Rha}), 157 \mathrm{~Hz}$ for the signal at 107.0 ppm (C-1, GlcUA), $169.8 \mathrm{~Hz}$ for the signal at $112.2 \mathrm{ppm}$ (C-1, Api) and $169.8 \mathrm{~Hz}$ for the signal at $112.5 \mathrm{ppm}$ (C-1, Api). ${ }^{10,11}$

The individual spin systems for the other monosaccharide residues were assigned with the aid of the correlations between the anomeric protons (or methyl signal, for rhamnose) and the remaining protons in 2D TOCSY and COSY spectra. The chemical shifts of the apiofuranosyl residues were identified on the basis of C-3 being quaternary carbons $(80.7,80.4 \mathrm{ppm})$ and $\mathrm{C}-4$ and C-5 being two methylenes. The assignments were double checked by comparison with literature chemical shift data and from HSQC and HMBC correlations. The sequence of the oligosaccharide chain was determined by a combination of DEPT, HSQC, HMQC, HMBC and T-ROESY experiments. Thus, the correlation observed in the HMBC spectrum between signals at 5.12 (H-1 rhamnose) and $75.4 \mathrm{ppm}$ (C-2 arabinose) indicated the linkage of the rhamnose residue to the position 2 of the arabinose residue. A correlation between signals at $5.12(\mathrm{H}-1$ rhamnose) and 3.80 (H-2 arabinose) in the T-ROESY spectrum confirm this glycosidic linkage. The connection of the two terminal apiofuranose residues to positions 3 and 4 of the rhamnose unit was confirmed by the following HMBC correlations: $3.62 \mathrm{ppm}$ (H-4 rhamnose) to $112.2 \mathrm{ppm}$ (C -1, apiofuranose); $3.76 \mathrm{ppm}$ (H-3 rhamnose) to 112.5 (C-1, apiofuranose). Finally, the HMBC correlation between the proton at 5.39 (H-1, arabinose) and C-28 confirms the location of the tetrasaccharide. Thus, Chiococcasaponin I (1) is a typical GOTCAB (glucuronide oleanane triterpenic type carboxylic acid 3,28-O-bisdesmoside) according to the classification of Tan et al. ${ }^{11}$

The HR-ESI-MS (positive mode) of chiococcasaponin II (2) exhibited a pseudomolecular ion peak $[\mathrm{M}+\mathrm{Na}]^{+}$at $\mathrm{m} / \mathrm{z}, 1063.5084$ and in the negative mode exhibited a pseudomolecular ion peak $[\mathrm{M}-\mathrm{H}]^{-}$at $\mathrm{m} / \mathrm{z}$ 1039.5122, both peaks being consistent with the molecular formula $\mathrm{C}_{52} \mathrm{H}_{80} \mathrm{O}_{21}$. Acid hydrolysis of $\mathbf{2}$ afforded the aglycone $3 \beta$-hydroxyolean-12, 15-dien-28-oic acid and the following monosaccharides: glucuronic acid, rhamnose, arabinose and apiose which were identified by GC/MS and TLC analysis. The hydrolysis reaction suggested the presence of the same sugar residues and aglycon as in $\mathbf{1}$. However, a comparison of the ${ }^{13} \mathrm{C}$ NMR, HSQC, HMBC and MS data indicated a difference between the sugar chain structures 1 and 2. Thus, the lack of five signals in the ${ }^{13} \mathrm{C}$ NMR spectrum and the anomeric signal at $5.29 \mathrm{ppm}$ in the ${ }^{1} \mathrm{H}$ NMR of $\mathbf{2}$ together with the 132 mass units of difference between Chiococcasaponin I (1) and Chiococcasaponin II (2) clearly indicates the absence of an apiofuranosyl residue in 2. It is worth of mention the upfield shift ( $c a .-7 \mathrm{ppm})$ observed for $\mathrm{C}-3$ in the rhamnose residue of $\mathbf{2}$ denoting absence of substitution at this site.

\section{Acknowledgments}

R.M. Borges acknowledges CNPq for the fellowship. The authors acknowledge Centro Nacional de Ressonância Magnética Nuclear de Macromoleculas Jiri Jonas, IBqM/ UFRJ for 400 and $600 \mathrm{MHz}$ NMR spectra.

\section{Supplementary Information}

Supplementary data are available free of charge at http://jbcs.sbq.org.br, as PDF file.

\section{References}

1. Mors, W. B.; Rizzini, C. T.; Pereira, N. A.; Medicinal Plants of Brazil, Reference Publications Inc.: Algonac Michigan, 2000.

2. Gazda, V. E.; Gomes-Carneiro, M. R.; Barbi, N. S.; Paumgartten, F. J. R.; J. Ethnopharmacol. 2006, 105, 187.

3. Abd El-Hafiz, M. A.; Weniger, B.; Quiron, J. C.; Anton, R.; Phytochemistry 1991, 30, 2029.

4. Bhattacharyya, J.; Cunha, E. V. L.; Phytochemistry 1992, 31, 2546.

5. Carbonezi, C. A.; Martins, D.; Young, M. C. M.; Lopes, M. N.; Furlan, M.; Rodrigues-Filho, E.; Bolzani, V. S.; Phytochemistry 1999, 51, 781.

6. Lopes, M. N.; de Oliveira, A. C.; Young, M. C. M.; Bolzani, V. S.; J. Braz. Chem. Soc. 2004, 15, 468.

7. El-Abbadi, N.; Weniger, B.; Lobstein, A.; Quirion, J. C.; Anton, R.; Planta Med. 1989, 55, 603.

8. Borges-Argáez, R.; Medina Baizabal, L.; May Pat, F.; Waterman, P. G.; Pena-Rodriguez, L. M.; J. Nat. Prod. 2001, 64, 228.

9. Harris, P. J.; Carbohydr. Res. 1992, 227, 365.

10. Agrawal, P. K.; Pathak, A. K.; Phytochem. Anal. 1996, 7, 113.

11. Tan, N.; Zhou, J.; Zhao, S.; Phytochemistry 1999, 52, 153.

Received: October 14, 2008 Web Release Date: September 25, 2009 


\section{Two New Oleanane Saponins from Chiococca alba (L.) Hitch.}

\section{Ricardo M. Borges, ${ }^{*, a}$ Luzineide W. Tinoco, ${ }^{a}$ José D. de Souza Filho, ${ }^{b}$ Nancy dos Santos Barbic and Antonio Jorge R. da Silva ${ }^{a}$}

${ }^{a}$ Núcleo de Pesquisas de Produtos Naturais and ${ }^{c}$ Faculdade de Farmácia, Centro de Ciências da Saúde, Universidade Federal do Rio de Janeiro, 21941-590 Rio de Janeiro-RJ, Brazil

${ }^{b}$ Departamento de Química, Instituto de Ciências Exatas, Universidade Federal de Minas Gerais 31270-901 Belo Horizonte-MG, Brazil

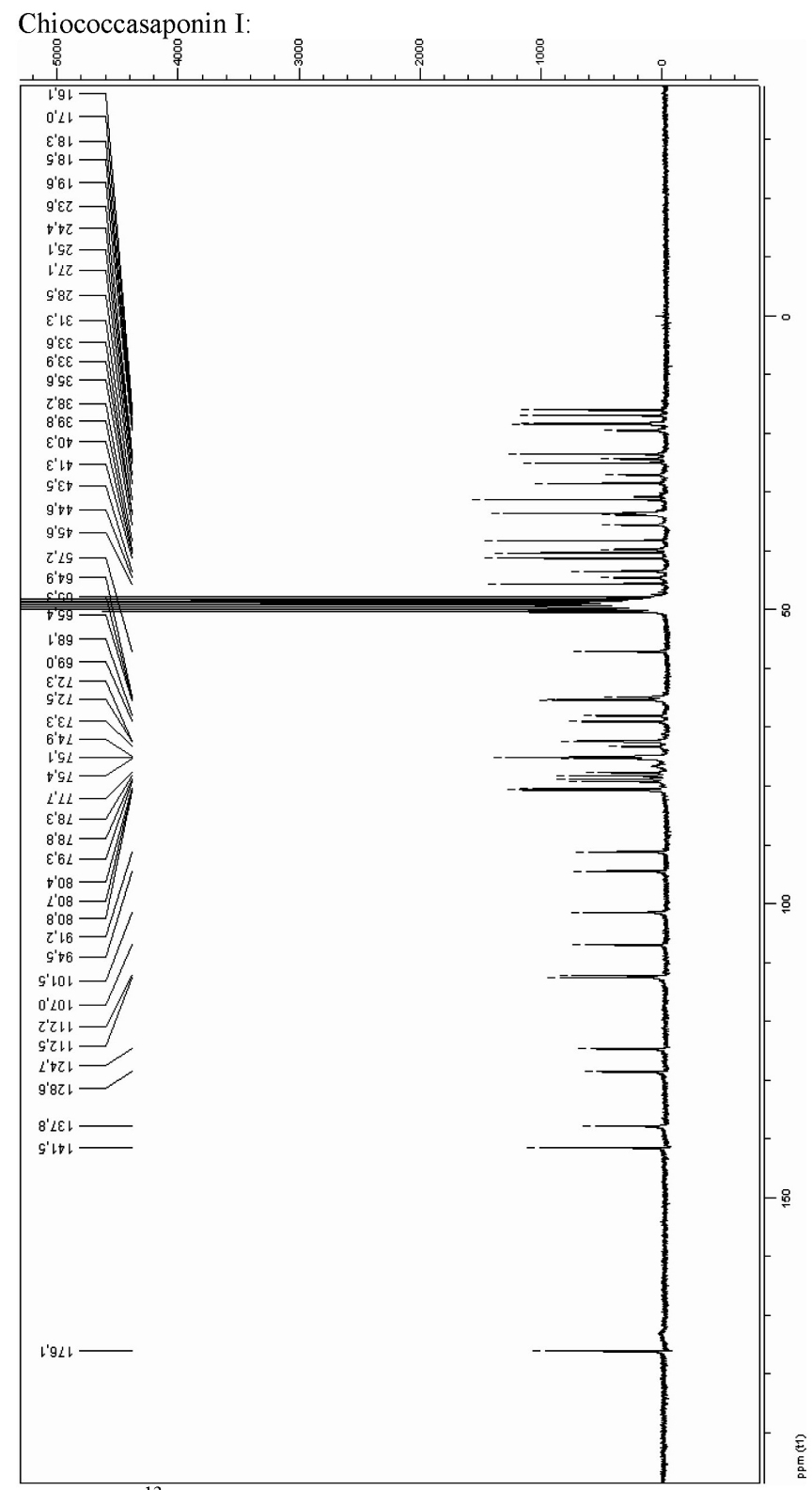

Figure S1. ${ }^{13} \mathrm{C}$ NMR of chiococcasaponin I. 


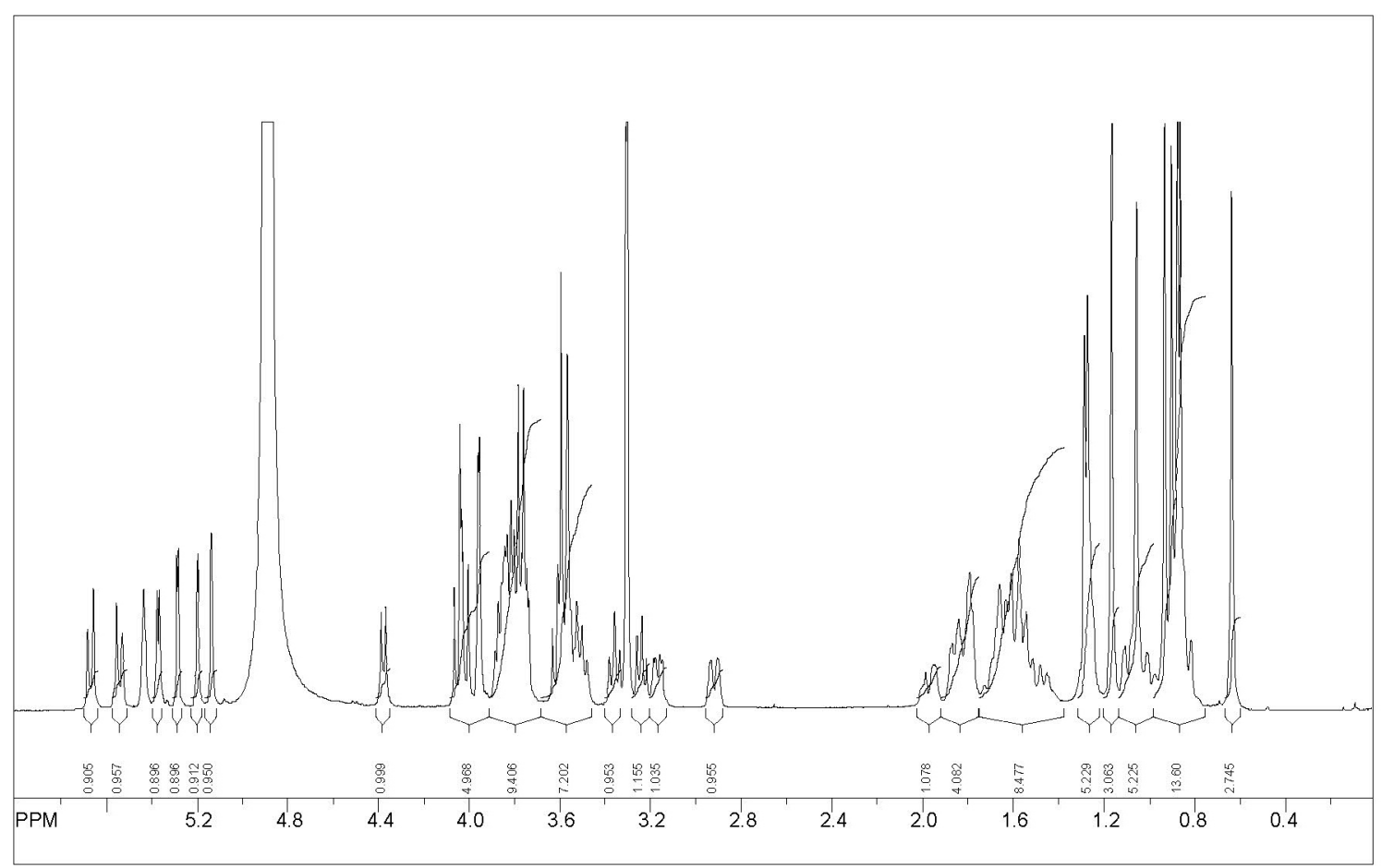

Figure S2. ${ }^{1} \mathrm{H}$ NMR of chiococcasaponin I.

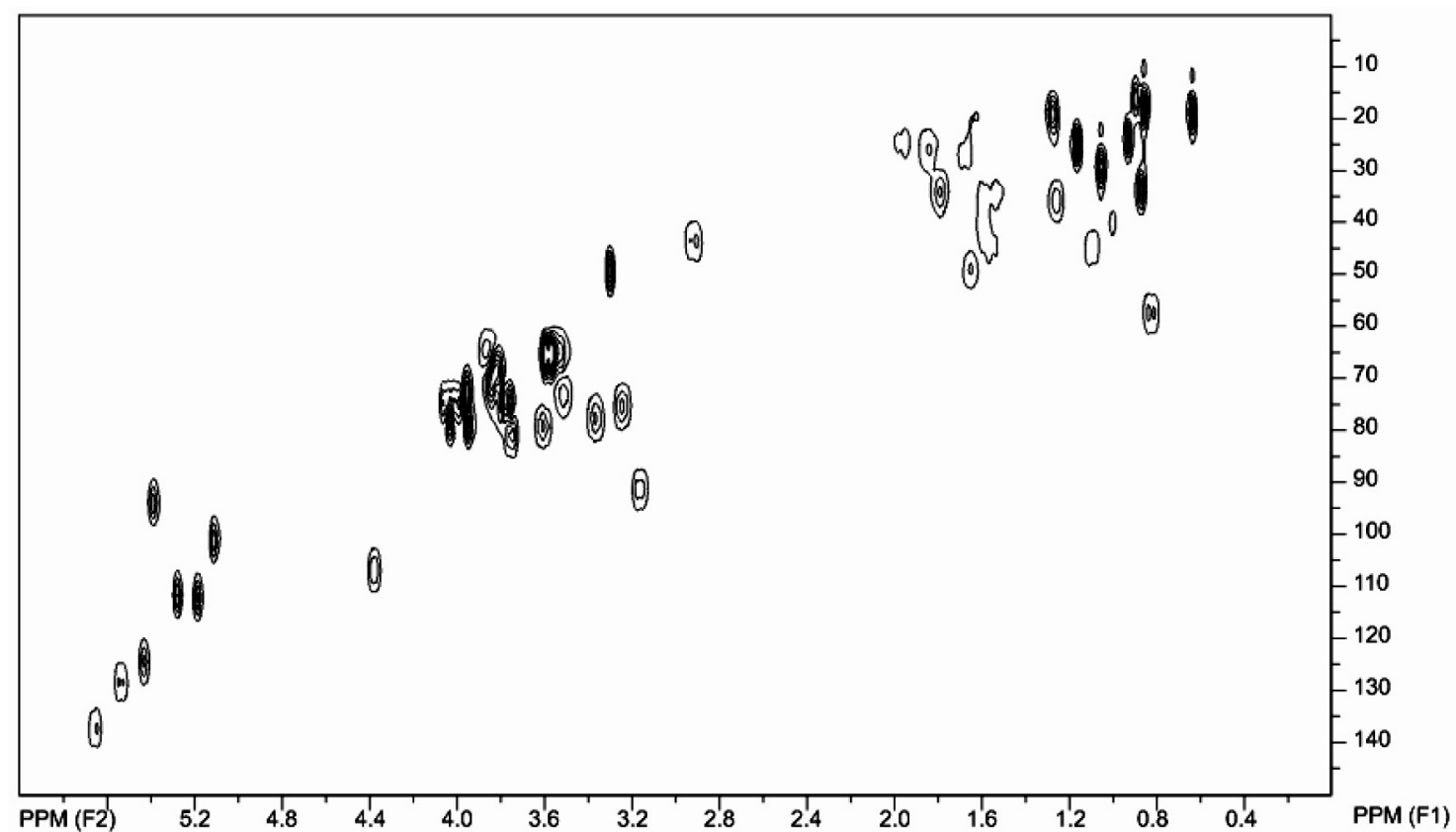

Figure S3. Edited HSQC of chiococcasaponin I. 


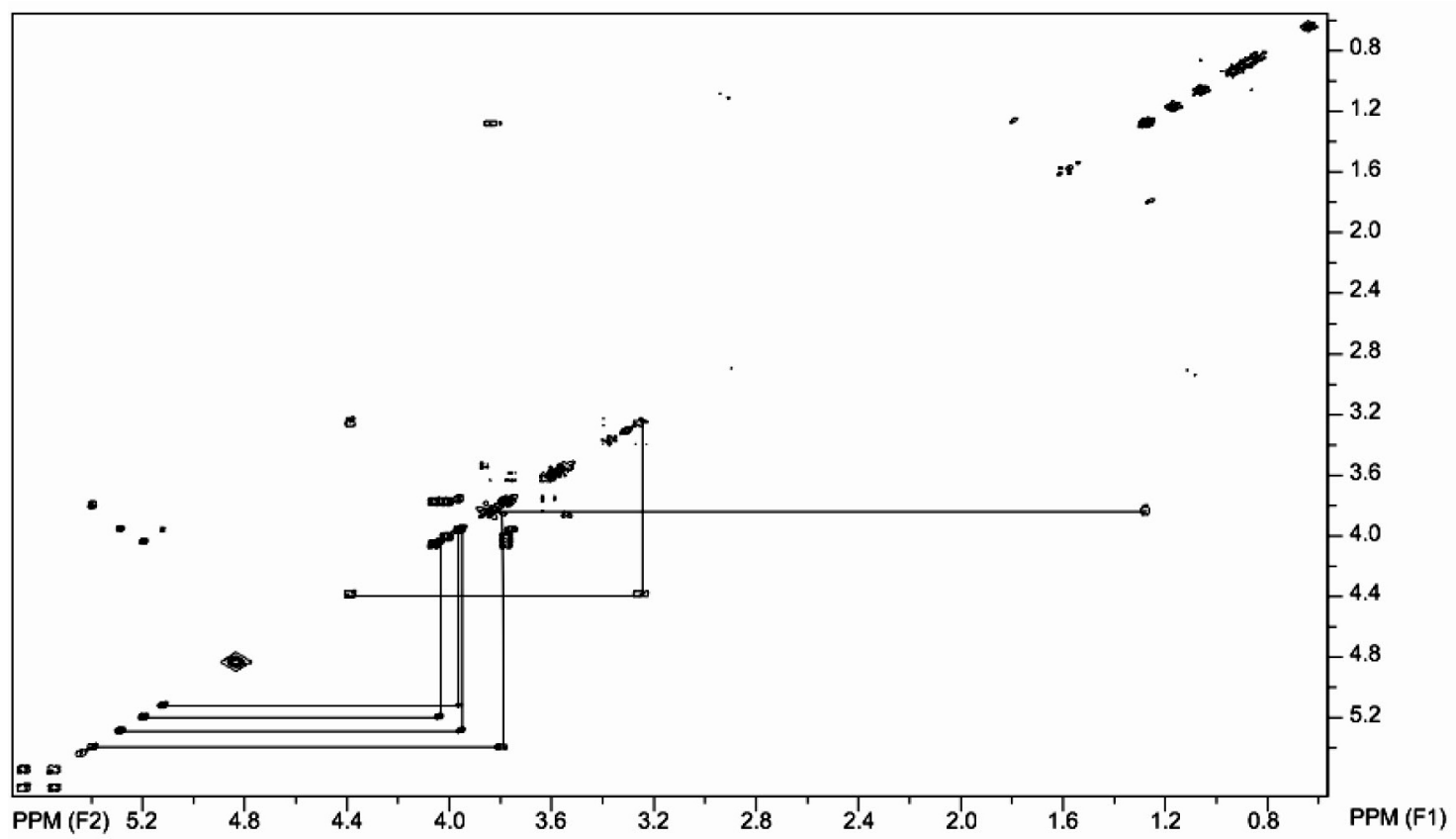

Figure S4. COSY of chiococcasaponin I.

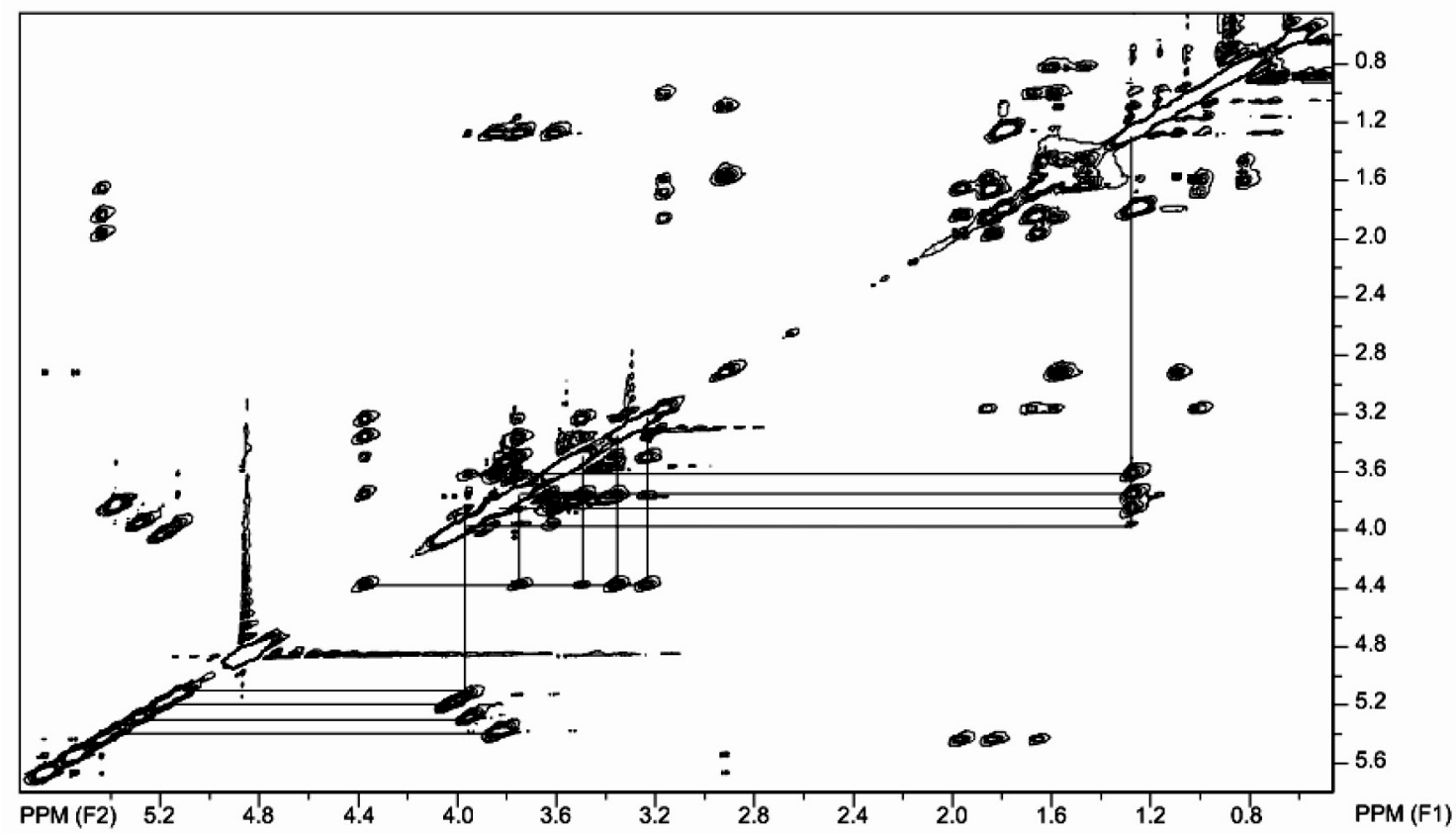

Figure S5. TOCSY of chiococcasaponin I. 


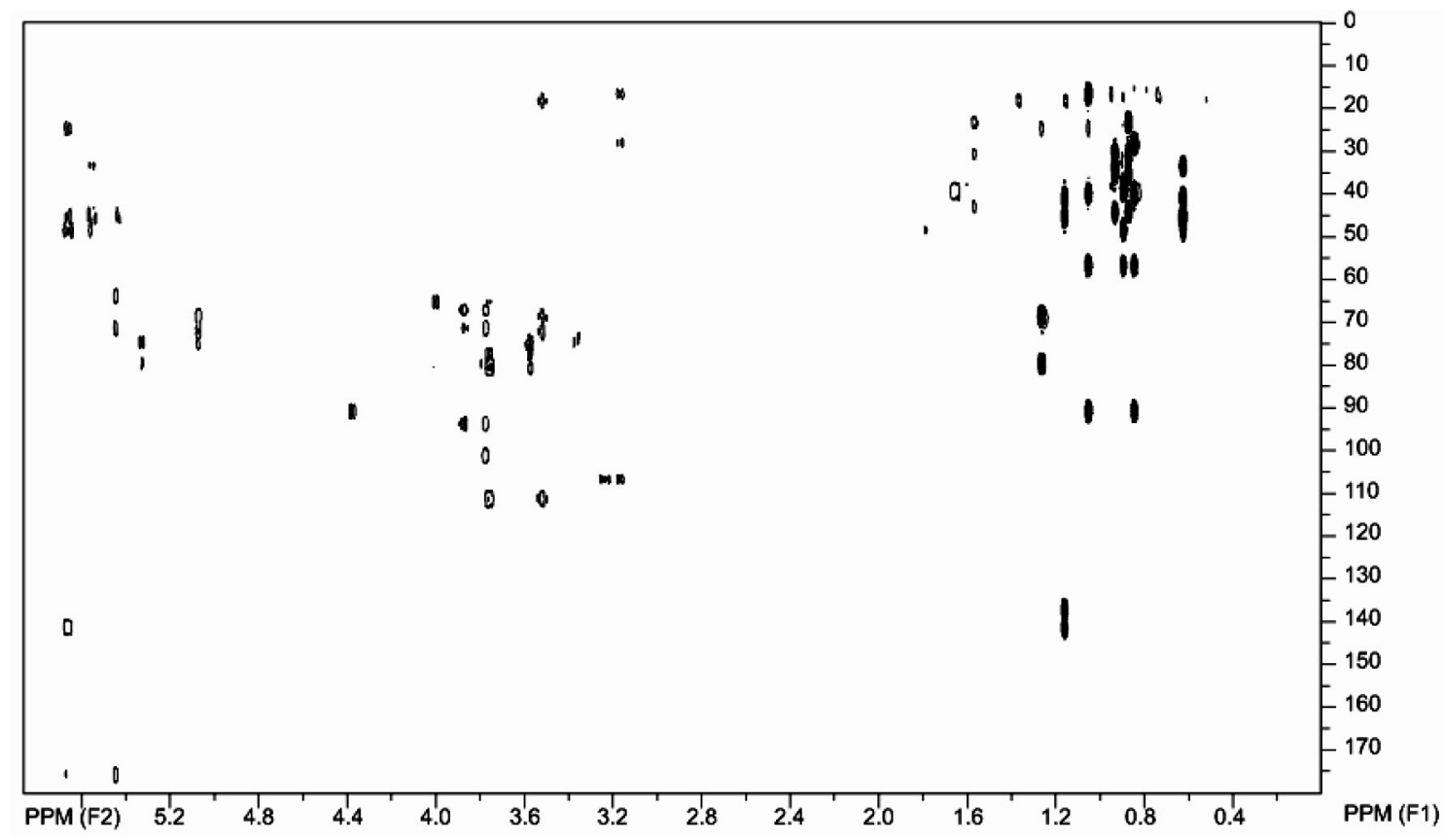

Figure S6. HMBC of chiococcasaponin I.

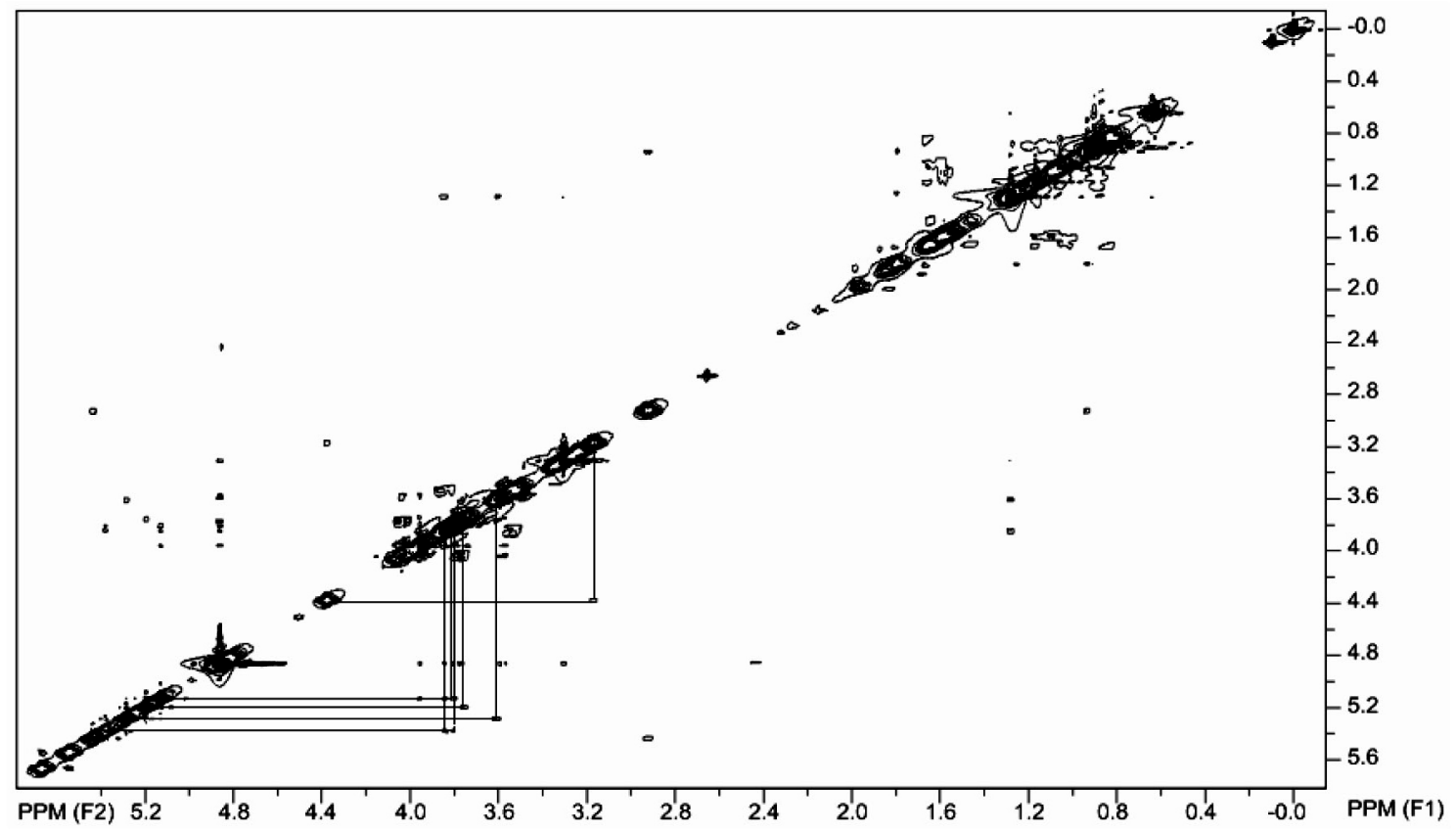

Figure S7. T-ROESY of chiococcasaponin I. 


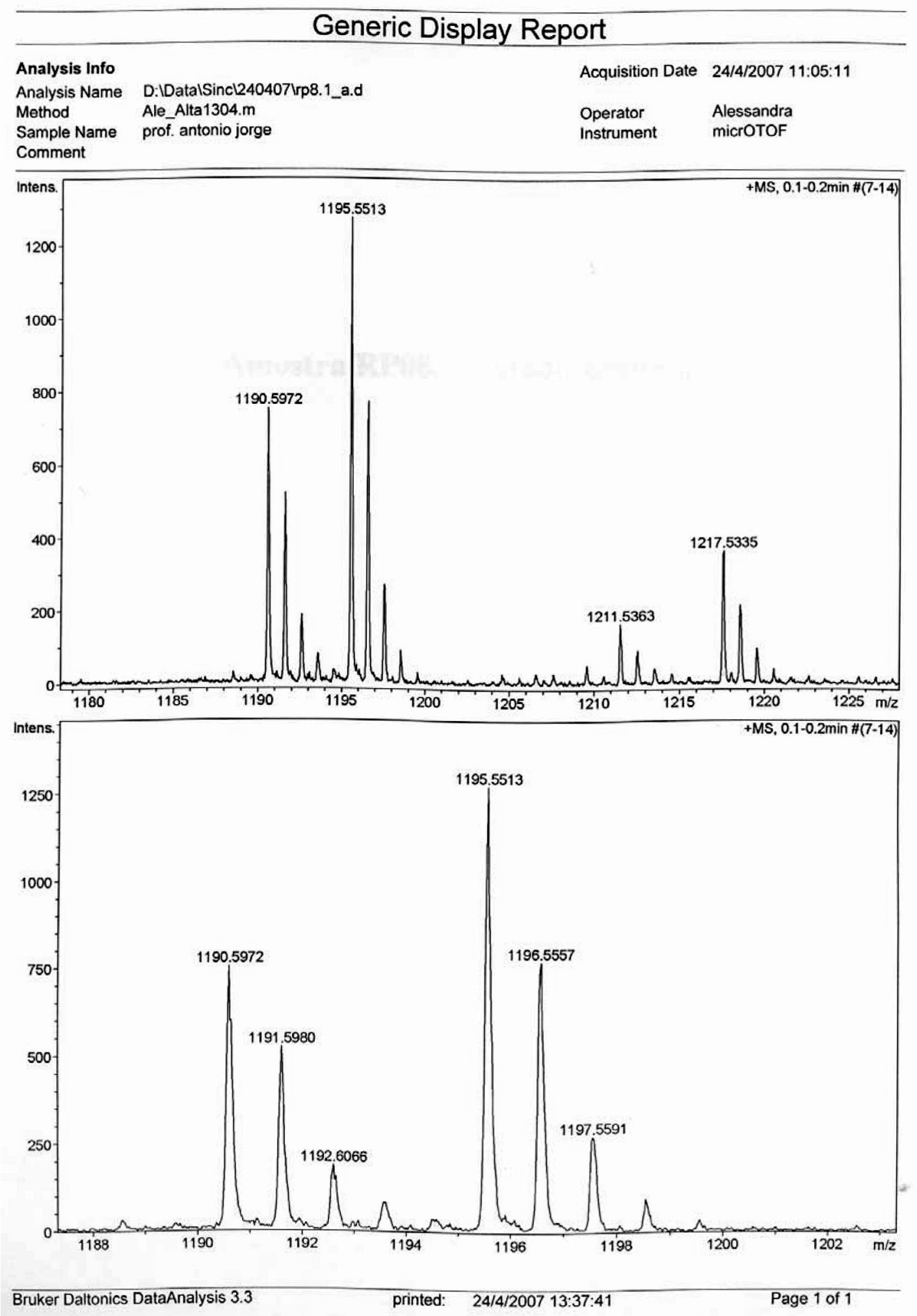

Figure S8. Mass spectrometry of Chiococcasaponin I (positive mode). 


\section{Generic Display Report}

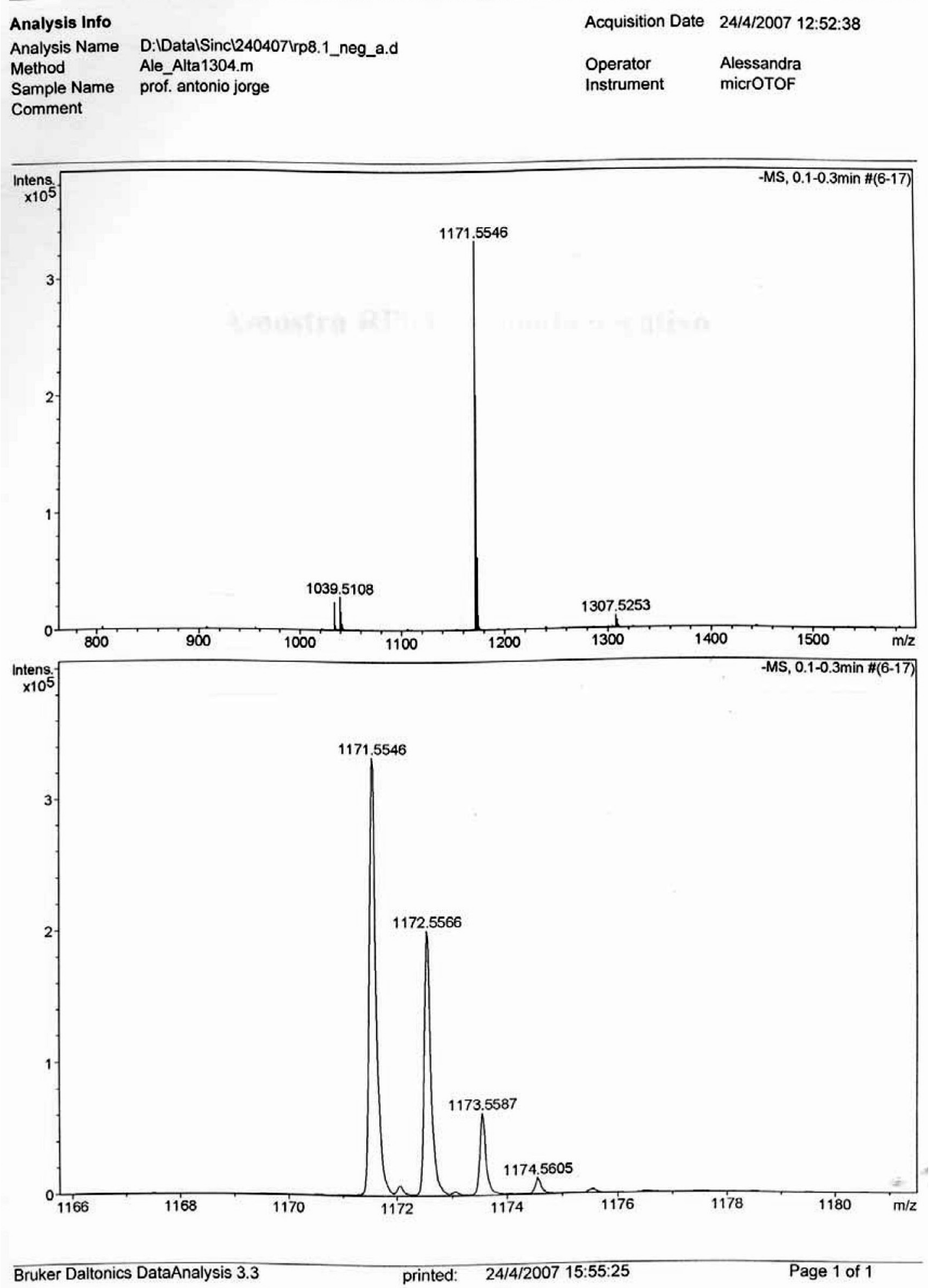

Figure S9. Mass spectrometry of Chiococcasaponin I (negative mode). 
Chiococcasaponin II:

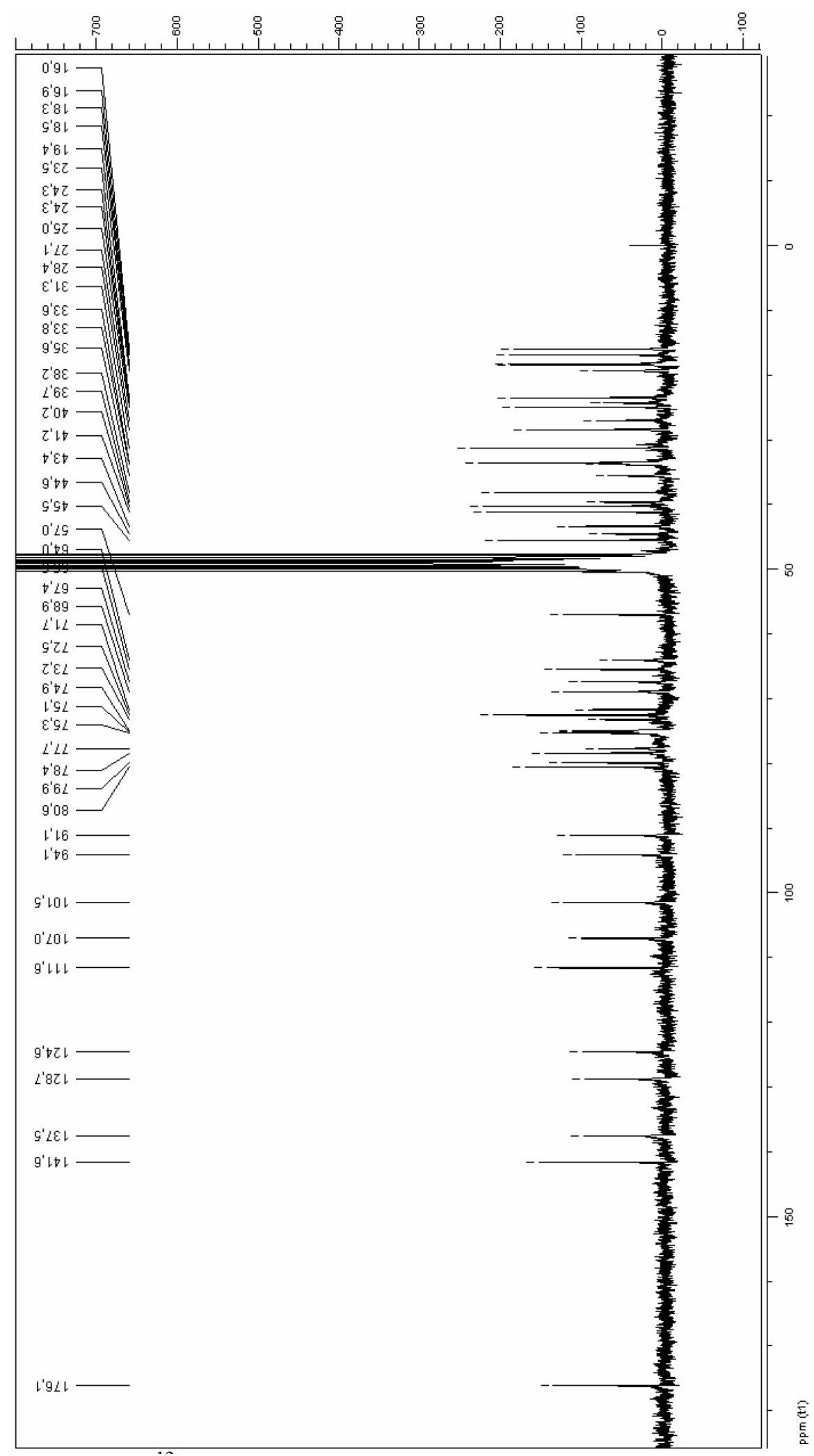

Figure S10. ${ }^{13} \mathrm{C}$ NMR of chiococcasaponin II. 


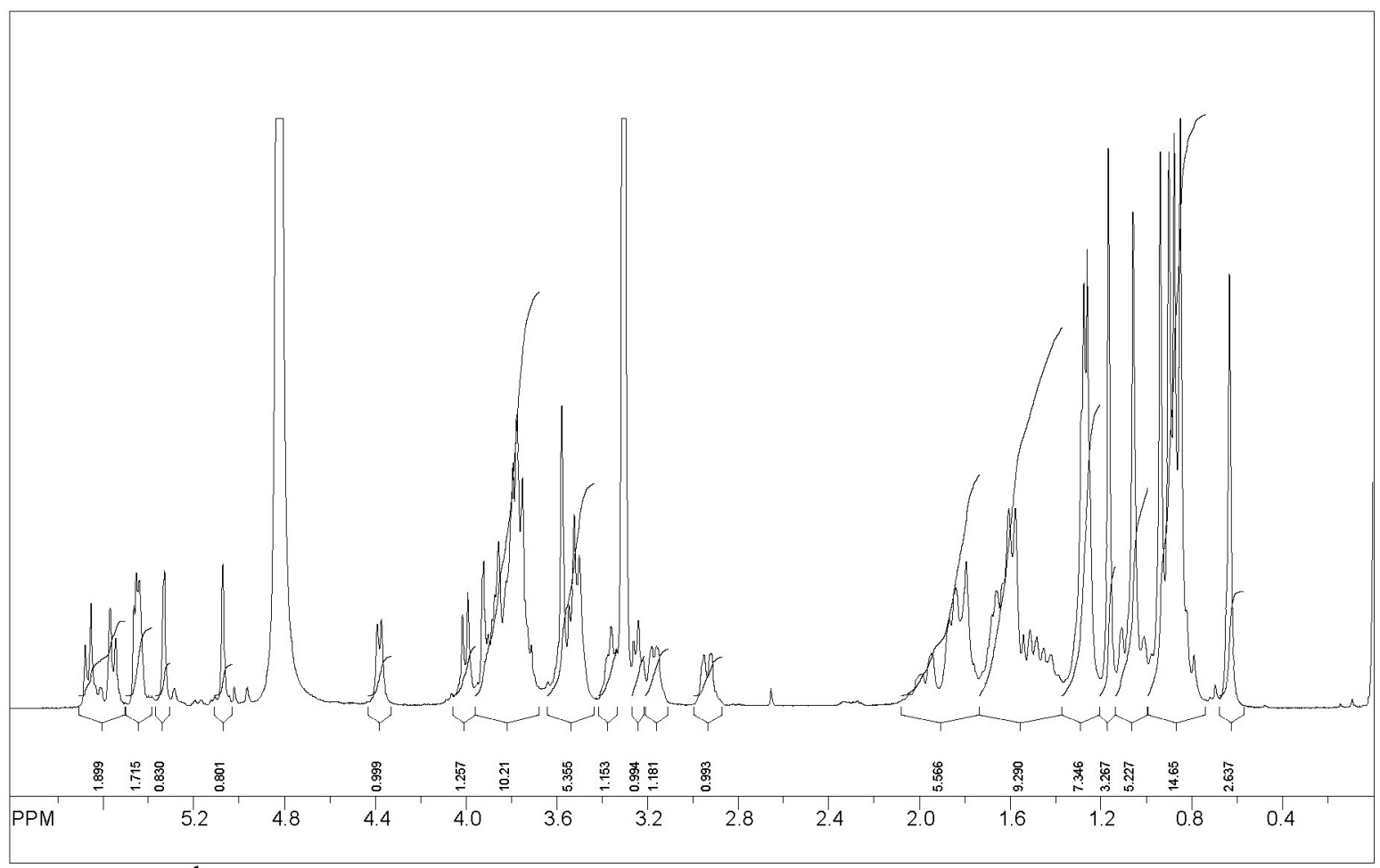

Figure S11. ${ }^{1} \mathrm{H}$ NMR of chiococcasaponin II.

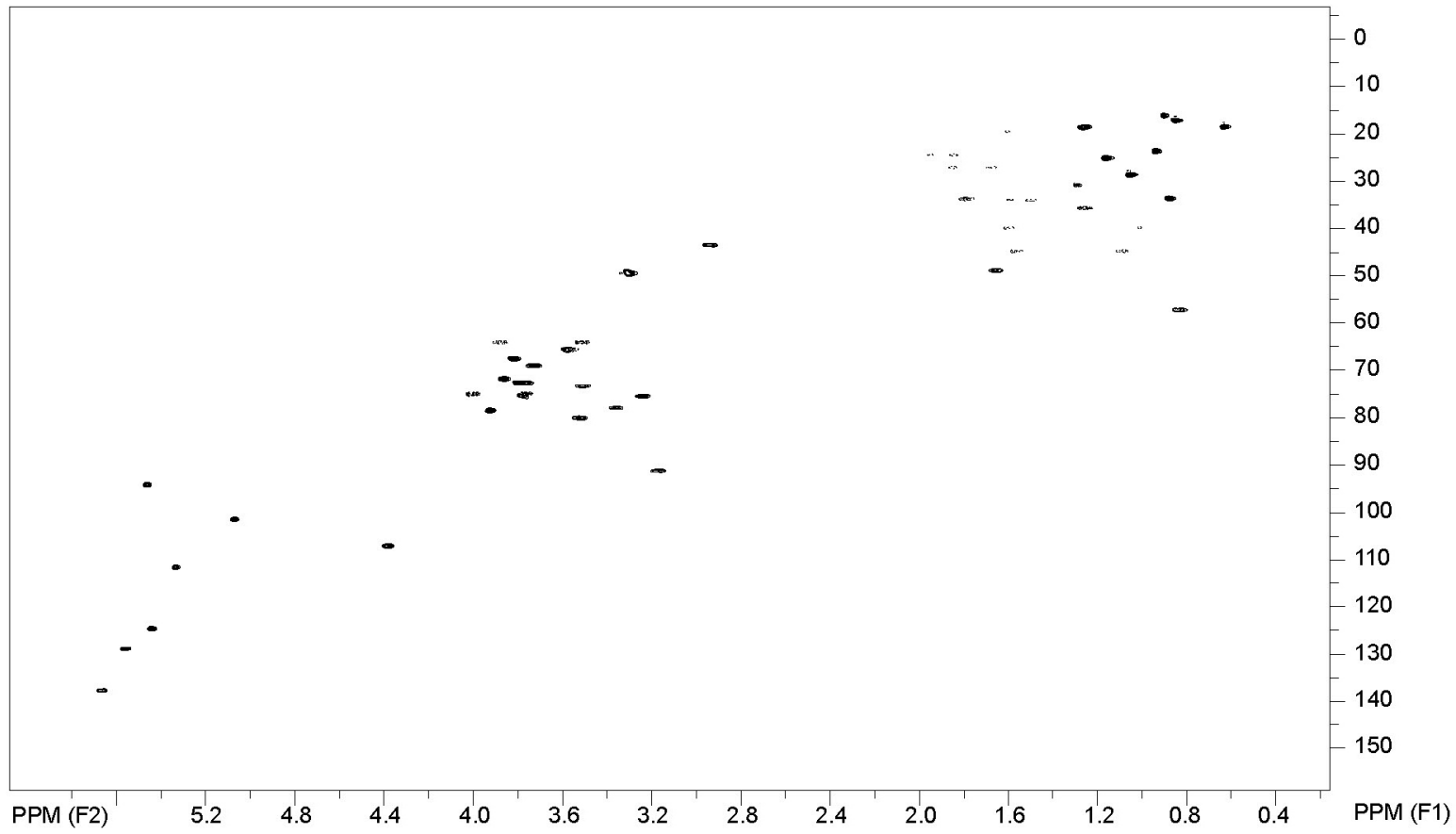

Figure S12. Edited HSQC of chiococcasaponin II. 


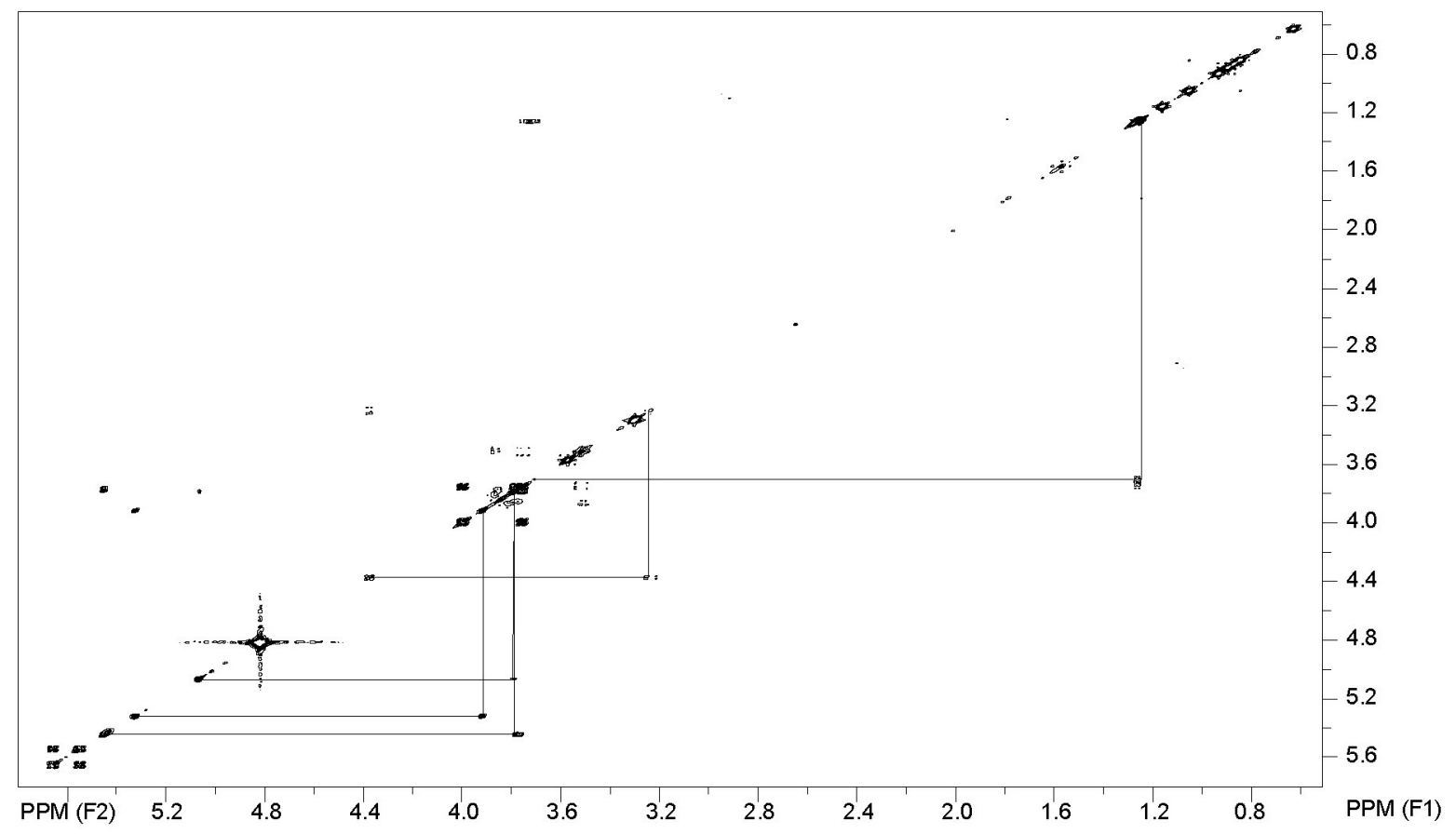

Figure S13. COSY of chiococcasaponin II.

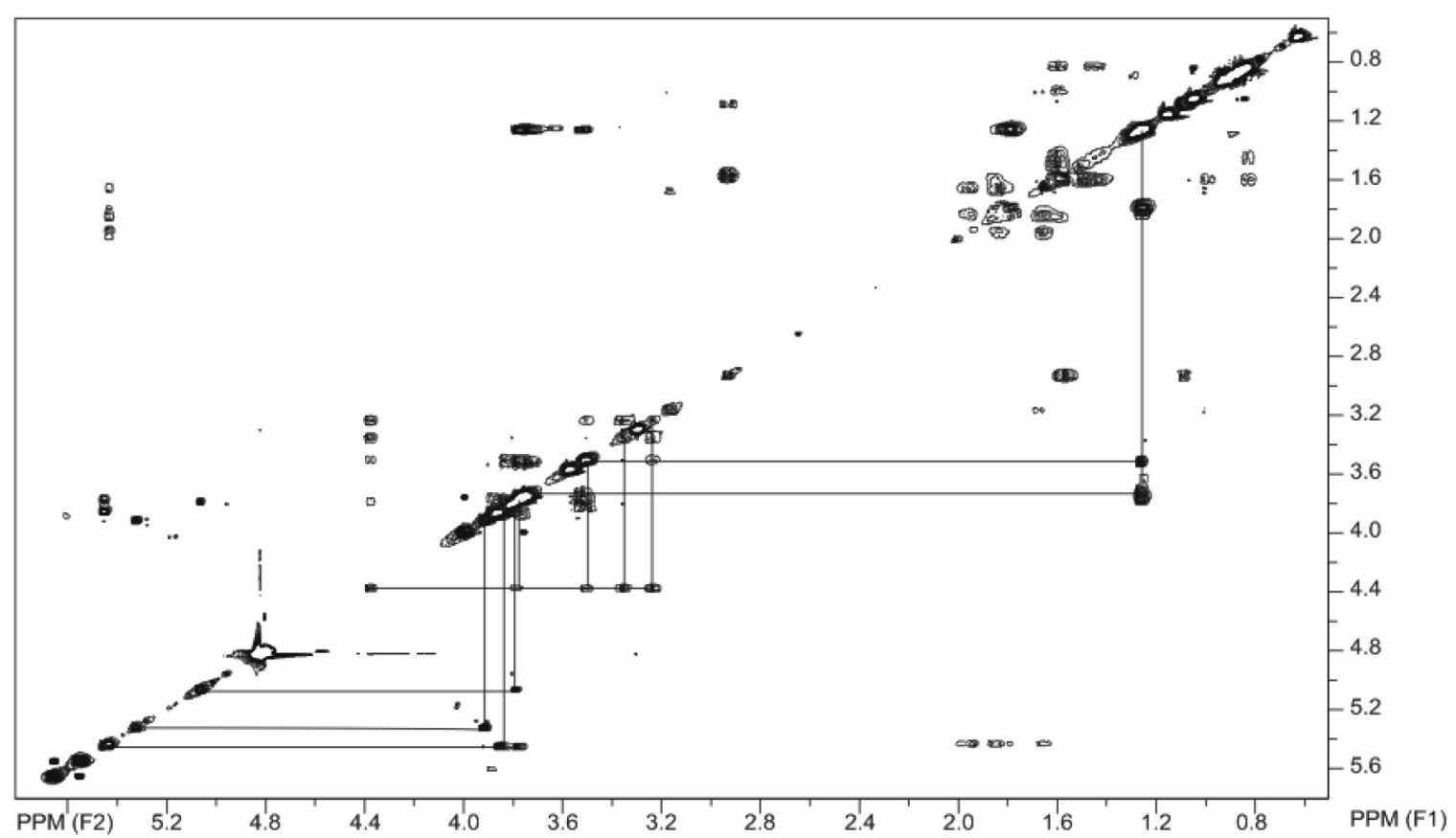

Figure S14. TOCSY of chiococcasaponin II. 


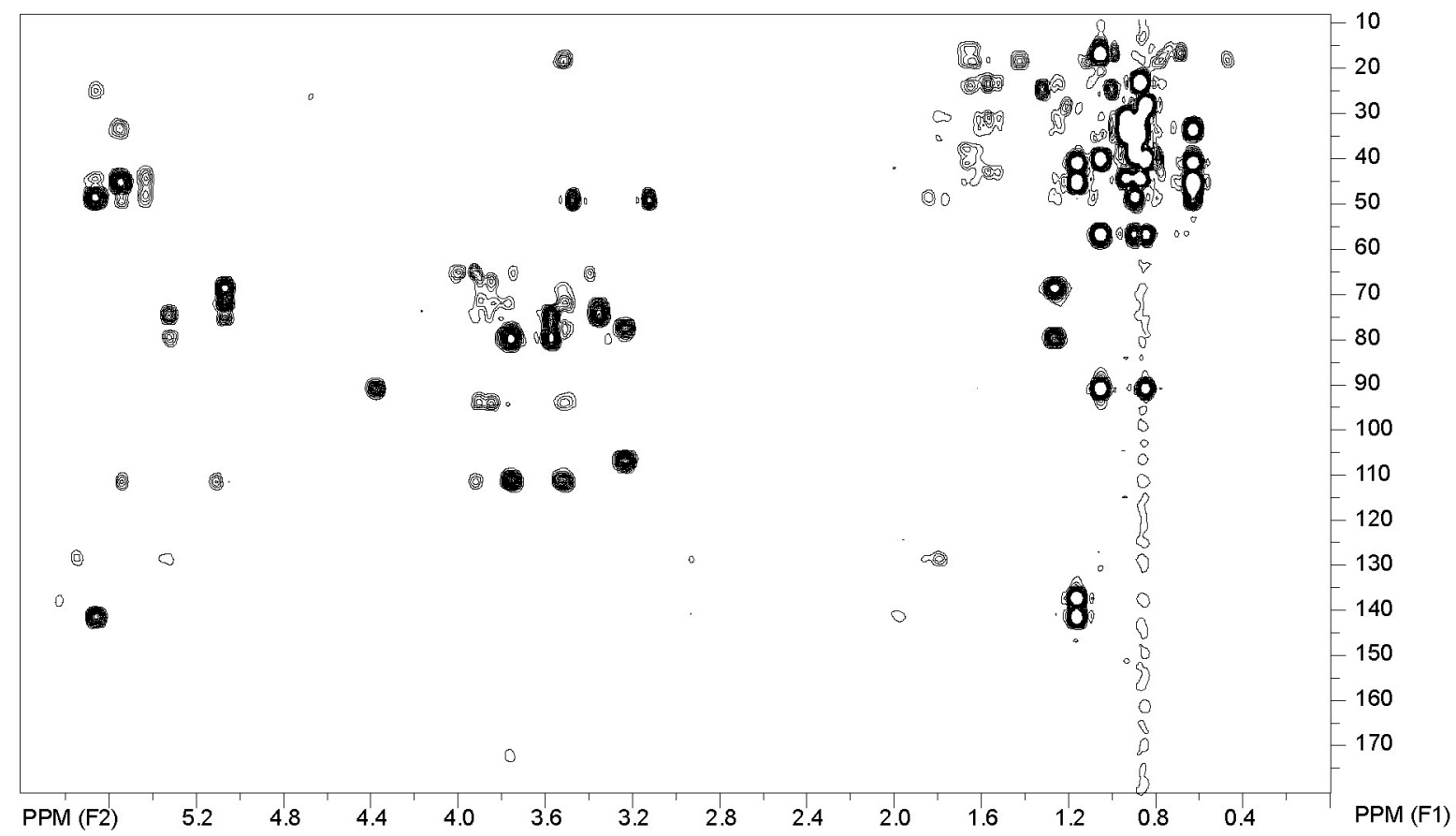

Figure S15. HMBC of chiococcasaponin II. 


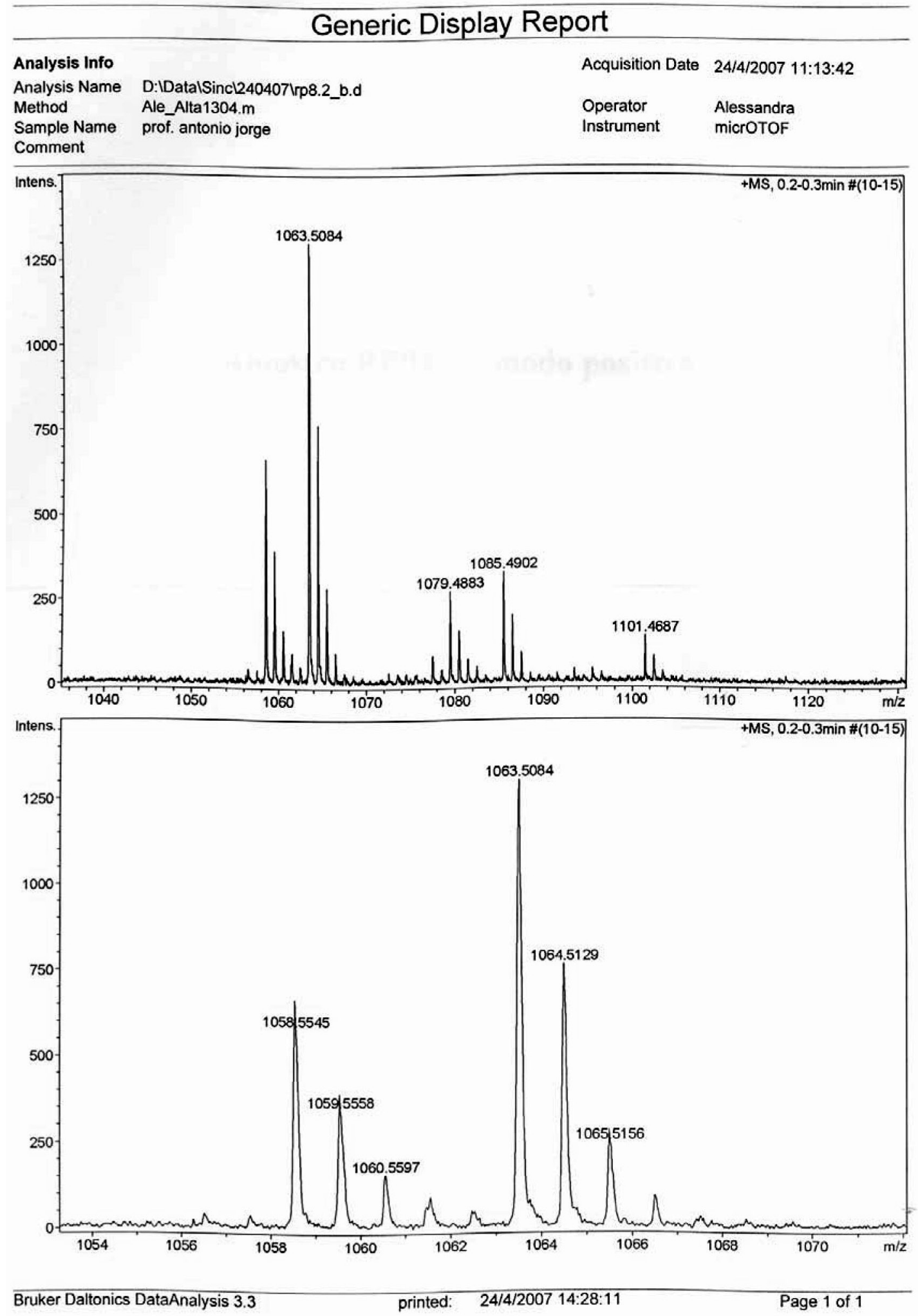

Figure S16. Mass spectrometry of Chiococcasaponin II (positive mode). 


\section{Generic Display Report}
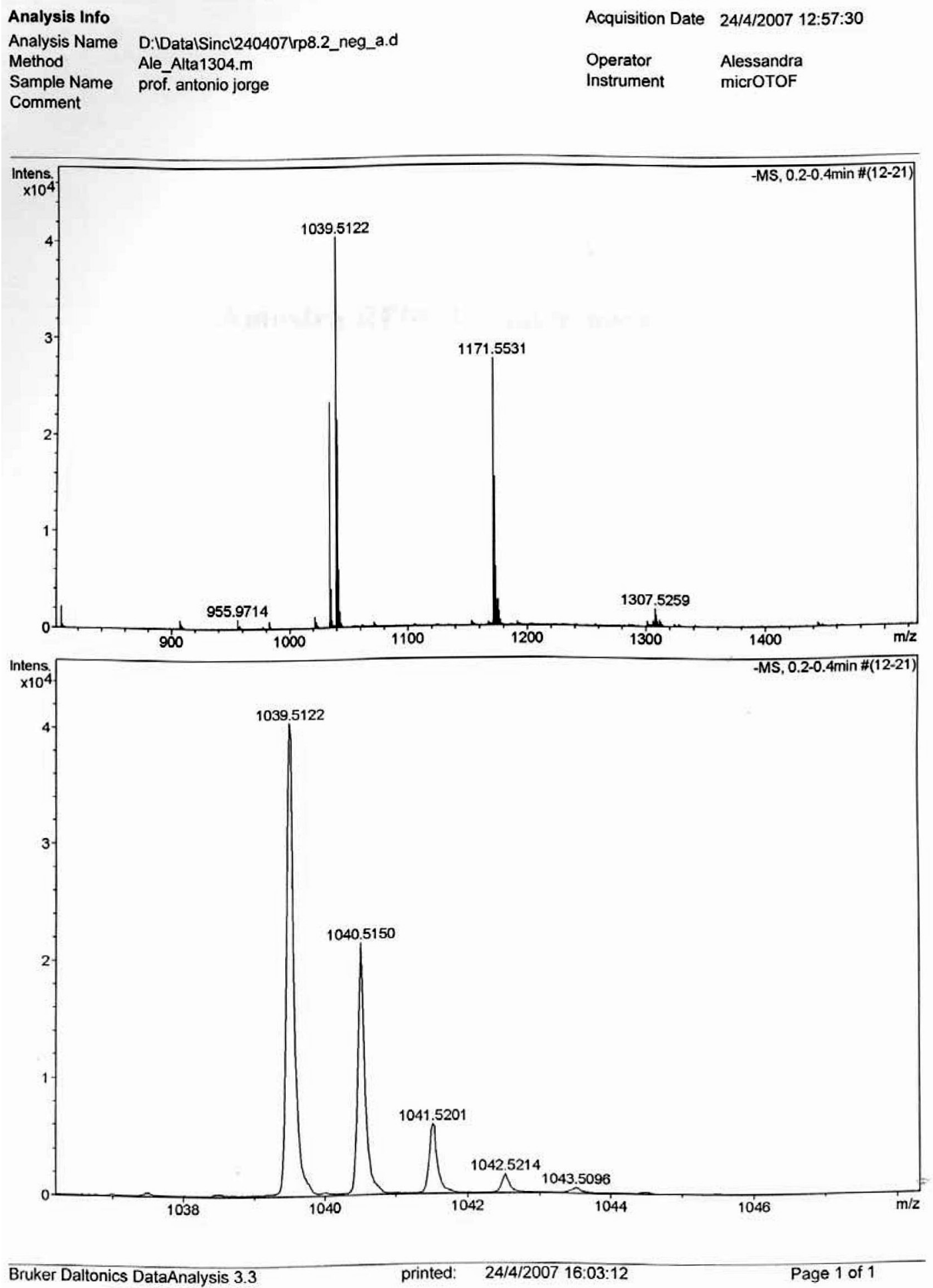

Figure S17. Mass spectrometry of Chiococcasaponin II (negative mode). 